\title{
Association of Substance Use With Behavioral Adherence to Centers for Disease Control and Prevention Guidelines for COVID-19 Mitigation: Cross-sectional Web-Based Survey
}

Mollie A Monnig ${ }^{1,2}, \mathrm{PhD}$; Hayley Treloar Padovano ${ }^{1,2,3}, \mathrm{PhD}$; Alexander W Sokolovsky ${ }^{1,2}, \mathrm{PhD}$; Grace DeCost ${ }^{2}$, MSc; Elizabeth R Aston ${ }^{1,2}$, PhD; Carolina L Haass-Koffler ${ }^{1,2,3}$, PharmD; Claire Szapary ${ }^{2}, \mathrm{BA}$; Patience Moyo ${ }^{2,4}$, PhD; Jaqueline C Avila $^{2}$, PhD; Jennifer W Tidey ${ }^{1,2,3}$, PhD; Peter M Monti ${ }^{1,2}$, PhD; Jasjit S Ahluwalia ${ }^{1,2}$, MD \author{
States

\section{Corresponding Author:} \\ Mollie A Monnig, PhD \\ Department of Behavioral and Social Sciences \\ Brown University \\ Box G-S121-5 \\ Providence, RI, 02912 \\ United States \\ Phone: 14018633491 \\ Email: mollie_monnig@brown.edu
}

${ }^{1}$ Department of Behavioral and Social Sciences, Brown University, Providence, RI, United States

${ }^{2}$ Center for Addiction and Disease Risk Exacerbation, Brown University, Providence, RI, United States

${ }^{3}$ Department of Psychiatry and Human Behavior, Brown University, Providence, RI, United States

${ }^{4}$ Center for Gerontology and Healthcare Research, Department of Health Services, Policy, and Practice, Brown University, Providence, RI, United

\section{Abstract}

Background: Substance use is a risk factor for COVID-19 infection and adverse outcomes. However, reasons for elevated risk for COVID-19 in substance users are not well understood.

Objective: The aim of this study was to evaluate whether alcohol or other drug use is associated with adherence to Centers for Disease Control and Prevention (CDC) guidelines for COVID-19 mitigation. Preregistered analyses tested the hypothesis that greater use of alcohol and other drugs would be associated with lower CDC guideline adherence. A secondary objective was to determine whether substance use was associated with the likelihood of COVID-19 testing or outcome.

Methods: A cross-sectional web-based survey was administered to a convenience sample recruited through Amazon's Mechanical Turk platform from June 18 to July 19, 2020. Individuals aged 18 years or older and residing in Connecticut, Massachusetts, New Jersey, New York, or Rhode Island were eligible to participate. The exposure of interest was past 7-day use of alcohol, cigarettes, electronic cigarettes, cannabis, stimulants, and nonmedical opioids. The primary outcome was CDC guideline adherence measured using a scale developed from behaviors advised to reduce the spread of COVID-19. Secondary outcomes were likelihood of COVID-19 testing and a positive COVID-19 test result. All analyses accounted for the sociodemographic characteristics.

Results: The sample consisted of 1084 individuals (mean age 40.9 [SD 13.4] years): 529 (48.8\%) men, 543 (50.1\%) women, $12(1.1 \%)$ other gender identity, $742(68.5 \%)$ White individuals, 267 (24.6\%) Black individuals, and $276(25.5 \%)$ Hispanic individuals. Daily opioid users reported lower CDC guideline adherence than nondaily users $(\mathrm{B}=-0.24,95 \% \mathrm{CI}-0.44$ to -0.05$)$ and nonusers $(\mathrm{B}=-0.57,95 \% \mathrm{CI}-0.76$ to -0.38$)$. Daily alcohol drinkers reported lower adherence than nondaily drinkers $(\mathrm{B}=-0.16$, $95 \% \mathrm{CI}-0.30$ to -0.02$)$. Nondaily alcohol drinkers reported higher adherence than nondrinkers $(\mathrm{B}=0.10,95 \% \mathrm{CI} 0.02-0.17)$. Daily opioid use was related to greater odds of COVID-19 testing, and daily stimulant use was related to greater odds of a positive COVID-19 test.

Conclusions: In a regionally-specific, racially, and ethnically diverse convenience sample, adults who engaged in daily alcohol or opioid use reported lower CDC guideline adherence for COVID-19 mitigation. Any opioid use was associated with greater odds of COVID-19 testing, and daily stimulant use was associated with greater odds of COVID-19 infection. Cigarettes, electronic cigarettes, cannabis, or stimulant use were not statistically associated with CDC guideline adherence, after accounting for 
sociodemographic covariates and other substance use variables. Findings support further investigation into whether COVID-19 testing and vaccination should be expanded among individuals with substance-related risk factors.

(JMIR Public Health Surveill 2021;7(11):e29319) doi: 10.2196/29319

\section{KEYWORDS}

SARS-CoV-2; novel coronavirus; COVID-19; alcohol use; alcohol drinking; opioid use; stimulant use; nicotine; smoking; survey; substance abuse; addiction; mental health; pandemic

\section{Introduction}

The use of alcohol, tobacco, and other drugs has been identified as a risk factor for infection with severe acute respiratory syndrome coronavirus 2 (SARS-CoV-2), the virus responsible for the COVID-19 pandemic [1,2]. Substance use may increase risk through both biological and behavioral pathways [3]. First, chronic use compromises the immune system and major organs, including cardiac, pulmonary, and renal systems [4,5]. Second, potential behavioral pathways for COVID-19 infection include decreased inhibition, increased risk-taking behavior, and competing contingencies (eg, perceived need to obtain and use substances despite risk of exposure) [6]. A recent study found that substance use disorder diagnosis was associated with greater risk of coronavirus infection (adjusted odds ratio 8.7) and higher death rates [1]. While this finding may be partially explained by higher rates of medical comorbidities that confer increased risk for and severity of COVID-19 among individuals with substance use disorder, behavioral factors were not assessed [1].

Emerging data indicate changes in substance use and related problems in the United States during the pandemic. In a Centers for Disease Control and Prevention (CDC) survey, 13\% of US adults reported initiating or increasing substance use to deal with COVID-19-related stress [7]. Another representative survey of US adults reported a $27 \%$ increase in average drinks per day and a $26 \%$ increase in frequency of binge drinking [8]. Smoking in young adults has shown signs of increased quit rates or reduced frequency overall, but increased quantity on use days $[9,10]$. Perhaps the starkest indicator is the increase in overdose deaths involving opioids, cocaine, and methamphetamine in 2020 [11,12].

The CDC recommends several behaviors to mitigate the spread of SARS-CoV-2, including avoiding close contact with others outside the household, handwashing, and wearing a face covering [13]. States have employed diverse mandates to control the spread of COVID-19, including limitations on social gatherings, business closures, and stay-at-home orders. Adherence to CDC guidelines and state mandates may be affected by substance use. For example, young adults under stay-at-home orders reported a higher number of in-person contacts outside the household on days they consumed alcohol [14]. Although other studies have assessed factors associated with adherence to COVID-19 mitigation behaviors, most have not addressed substance use $[15,16]$. Because the pandemic itself appears to be associated with increases in some types of substance use, understanding whether substance use is associated with lower adherence to CDC mitigation guidelines is pressing. Finding an association between substance use and suboptimal preventive behaviors would help to identify specific at-risk groups and to generate hypotheses on mechanisms underlying nonadherence to guidelines.

The objective of this study was to investigate links between use of specific substances and behavioral adherence to CDC guidelines in a sample of US adults surveyed in June and July 2020. Our main hypothesis predicted that greater substance use would be associated with lower CDC guideline adherence after accounting for demographic and contextual factors that have been associated with CDC guideline adherence or related health behaviors in previous studies, such as age and income [15-19]. Given that lower guideline adherence would have an expected association with COVID-19 exposure and infection, secondary analyses tested whether substance use was associated with the likelihood of receiving a COVID-19 test or with the outcome of testing.

\section{Methods}

\section{Study Design and Data Source}

This study was a deidentified, web-based, cross-sectional survey with a nonprobability sample. Participants were recruited using Amazon's Mechanical Turk (MTurk) platform. MTurk is a crowdsourcing platform with a built-in survey administration system that allows researchers access to a pool of $>200,000$ potential respondents, producing data of quality equal to or better than professionally sourced panels [20-23]. Our study focused on 5 northeastern states (Connecticut, Massachusetts, New Jersey, New York, and Rhode Island) that had the highest numbers of COVID-19 cases and deaths per capita in the United States at the time [24]. A pilot was released on May 27, 2020, for survey refinement. The final survey was released from June 18 to July 19,2020 , at which time the 5 states had restrictions on business capacity and social gatherings (see Table S1 in Multimedia Appendix 1). This study was an initiative of the Center for Addiction and Disease Risk Exacerbation to examine the link between substance use and disease [25].

\section{Participants}

Eligibility criteria were as follows: $\geq 18$ years of age, residing in an eligible state (Connecticut, Massachusetts, New Jersey, New York, or Rhode Island), and holding an active MTurk account. Quotas based on age, gender, race, and ethnicity were used to ensure a diverse sample. Black and Hispanic individuals were oversampled owing to overwhelming evidence that such individuals have been disproportionately affected by the pandemic [26-30]. Race and ethnicity quotas were as follows: $40 \%$ non-Hispanic White, 25\% Hispanic non-Black, 25\% Black any ethnicity, and $10 \%$ non-Hispanic non-White. Within each racial/ethnic group, the following age quotas were applied: $10 \%$, 
18-25 years; 20\%, 25-35 years; 20\%, 35-45 years; 25\%, 45-55 years; and $25 \%, \geq 55$ years. Percentages were allocated to each age range (which are preset in the MTurk system) to ensure broad representation of ages and specifically to avoid the underrepresentation of older adults often observed in web-based survey studies [31]. Within each cell type based on race/ethnicity and age, quotas stipulated equal numbers of men and women. Interested individuals completed a brief screening survey to assess demographics and were directed to the main survey if their quotas were not already filled. Participants provided written informed consent before beginning the survey. Participants were paid US \$10 upon completion. This study was reviewed by the Brown University Institutional Review Board and was determined to be exempt from requiring Institutional Review Board approval as a minimal risk study per federal regulations.

\section{Measurements}

\section{Sociodemographic Characteristics}

Demographic characteristics included age, sex, gender identity, highest level of education, annual household income, and home ownership. These variables have demonstrated associations with adherence to COVID-19 prevention/mitigation behaviors in US adults in previous research [15-18] aside from home ownership, a proxy for wealth, which was chosen due to relations with health behaviors in other contexts [19]. Race and ethnicity were assessed with a two-item measure from the 2020 Household Pulse Survey [32]. Individuals indicated whether they were Hispanic, Latino, or of Spanish origin, and selected all races that applied. Participants were asked essential worker status, defined as "someone whose work is critical to business operations and/or meeting basic human needs and is required to attend work during the COVID pandemic" (yes/no/not sure).

\section{Primary Outcome: CDC Guideline Adherence}

The primary outcome was measured using a self-report questionnaire that we developed from the CDC's recommendations for behaviors in which the public should engage to mitigate COVID-19 transmission (see Table 1). Participants rated how often they engaged in 13 recommended behaviors during the past 4 weeks on a scale from 0 (rarely or never) to 3 (always), with higher scores representing higher adherence. Parallel analysis and inspection of factor loadings supported use of the total item average as a unidimensional construct reflecting CDC guideline adherence. The internal consistency reliability was excellent (Cronbach $\alpha .91)$.

Table 1. Primary outcome: Centers for Disease Control and Prevention guideline adherence measure. ${ }^{\mathrm{a}}$

\begin{tabular}{ll}
\hline During the past 4 weeks, how often did you... & Always Usually Sometimes Rarely or Never \\
\hline
\end{tabular}

Wash your hands often with soap and water for at least 20 seconds especially after you have been

in a public place, or after blowing your nose, coughing, or sneezing?

Use hand sanitizer that contains at least $60 \%$ alcohol when soap and water was not readily available?

Avoid touching your eyes, nose, and mouth?

Avoid close contact with people who are sick?

Remain at least 6 feet away from other people when in public?

Stay home as much as possible?

Use a cloth face cover over your nose and mouth when in public?

Cover your mouth and nose with a tissue or use the inside of your elbow when you coughed or sneezed?

Throw used tissues in the trash?

Immediately wash your hands with soap and water for at least 20 seconds after coughing or sneezing?

Clean and disinfectant frequently touched surfaces in your home (eg, tables, doorknobs, light switches, countertops, desks, phones, toilets, faucets)?

Use detergent or soap and water to clean dirty surfaces before disinfection?

When cleaning surfaces, how often did you use any of the following: a diluted household bleach, a solution that was at least $70 \%$ alcohol, or another $\mathrm{EPA}^{\mathrm{b}}$-registered household disinfectant?

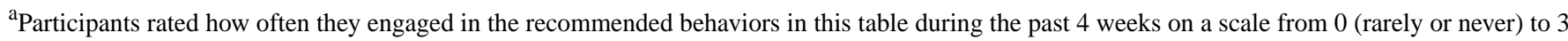
(always), with higher scores representing higher adherence.

${ }^{\mathrm{b}}$ EPA: Environmental Protection Agency.

\section{Secondary Outcome: COVID-19 Exposure and Testing}

COVID-19 testing and test results were the secondary outcomes. Testing history was assessed by asking "Have you been tested for the novel coronavirus or COVID-19?" (yes/no/not sure). Answering "yes" prompted these follow-up questions: "Have you had a nose swab test for the virus that causes COVID-19?" and "Have you had a blood test to see if you already had the virus ("serology")?" Each of these were followed with the question, "If yes, what was your result?" 


\section{Substance Use}

Substance use was recorded using the Timeline Followback method [33] for the 7 days preceding survey completion. If the participant endorsed any use of cigarettes, electronic cigarettes (e-cigarettes), cannabis, alcohol, opioids, or stimulants, the participant was asked to report whether the substance was used on each day in the past week. For opioids only, participants were instructed, "Do not report any drug that was taken as directed by a physician." Past 7-day frequencies of alcohol, cigarette, e-cigarette, cannabis, stimulant, and nonmedical opioid use were recoded to reflect no use, 1-6 days of use, and daily use.

\section{Statistical Analysis}

The analytic plan was preregistered and can be accessed online [34]. A descriptive analysis assessed the univariate distributions of demographic characteristics, substance use variables, COVID-19 testing, and the CDC guideline adherence outcome. Continuous data were reported as mean (SD), and categorical variables were reported as count (percentage). Distributional properties of outcomes informed model selection. Code and data analysis were generated using SAS software, Version 9.4 for Windows (Copyright 2016 by SAS Institute Inc), and R version 4.0.3 [35]. Independent variables accounting for CDC guideline adherence score were evaluated using a general linear model with a continuous outcome and categorical and continuous independent variables. Preregistered covariates tested for inclusion included age (continuous), education (high school or less [reference], some college/1-year degree, college graduate/4-year degree, graduate or professional degree), gender (cisgender female [reference], cisgender male, other gender identity, or prefer not to answer), race (White [reference], Black or African American, Asian, other or more than one racial identity), ethnicity (not Hispanic or Latino [reference], Hispanic or Latino), essential worker status (not essential worker or unsure [reference], essential worker), income (8 ordered categories, treated as continuous), household size (continuous, truncated at 6 maximum), dwelling ownership (no ownership [reference], 1=ownership), and COVID-19 test (no test or unsure [reference]; yes, test negative; yes, test positive). Covariates that were not related to CDC guideline adherence in omnibus Type III sums of squares tests were removed and models retested. Next, focal substance use variables reflecting no use, 1-6 days of use, and daily use of alcohol, cigarettes, e-cigarettes, cannabis, stimulants, and nonmedical opioids were added. Substance use variables that were not related to CDC guideline adherence were removed and models retested. Follow-up two-sided $t$ tests compared daily use to 1-6 day and no use categories and 1-6 days of use to no use. Adjusted $R^{2}$ and $\Delta R^{2}$ evaluated the proportion of variability in CDC guideline adherence accounted for by variables included in the models.
A secondary set of logistic regression models tested associations of covariates and substance use variables with the likelihood of COVID-19 testing and results. An initial logistic model evaluated the likelihood of COVID-19 testing $(0=$ no test or unsure, $1=$ test). Differences in testing likelihood according to substance use frequency prompted post hoc analyses on possible explanatory factors. The post hoc analyses used independent two-sided $t$ tests for continuous variables and Pearson $\chi^{2}$ tests for categorical variables. A subset analysis among those who reported a COVID-19 test evaluated the likelihood of a positive test result $(0=$ negative, $1=$ positive $)$. Covariates that were not related to COVID-19 testing or COVID-19 test results in omnibus Type III sums of squares tests were removed and models retested.

\section{Results}

\section{Demographic Characteristics of the Participants}

Of the 3849 individuals who were assessed for eligibility, 1185 completed the entire survey (see Figure 1). Data sets were excluded from the analysis if the participant did not pass at least 2 of the 3 validity checks embedded in the survey, for example, Please select the response "strongly agree" $(n=12)$ or if the participant endorsed implausible or mutually exclusive responses on demographic items $(n=18)$. Duplicate data (ie, multiple responses from the same individual) were identified in 17 cases and were removed from the data set. Final models had 1084 participants after excluding participants with missing data for covariates. Demographic information for the evaluable data set including 1084 participants is provided in Table 2. Half of the study sample was males, and the mean age was 40.9 years. The majority of the sample consisted of Whites and had a college degree. Black individuals made up 24.6\% (267/1084) of the sample and $25.5 \%(276 / 1084)$ of the participants identified as Hispanic. Approximately one-quarter of the sample had a history of COVID-19 testing. Of those who received a test, $15.8 \%$ $(44 / 279)$ had a positive result. Of the 1084 participants, 700 $(64.6 \%)$ reported substance use in the past 7 days. Cigarettes were the most common substance used daily, followed by alcohol and opioids. One-third of the sample reported nondaily alcohol use. The majority reported monosubstance use $(382 / 1084,35.2 \%)$, and alcohol was the most common single substance used $(252 / 1084,23.2 \%)$. Polysubstance use (2 or more substances) was reported by 318 individuals (29.3\%). The most common combinations of substances were alcohol and opioids (41/1084, 3.8\%), alcohol and cigarettes (36/1084, 3.3\%), opioids and cigarettes (35/1084, 3.2\%), and alcohol and marijuana $(23 / 1084,2.1 \%)$. Other polysubstance combinations were reported by $<2 \%$ of the sample $(<22$ individuals per cell). 
Figure 1. Sample selection of residents of Connecticut, Massachusetts, New Jersey, New York, and Rhode Island for a web-based survey of health behaviors and Centers for Disease Control and Prevention guideline adherence in June-July 2020.

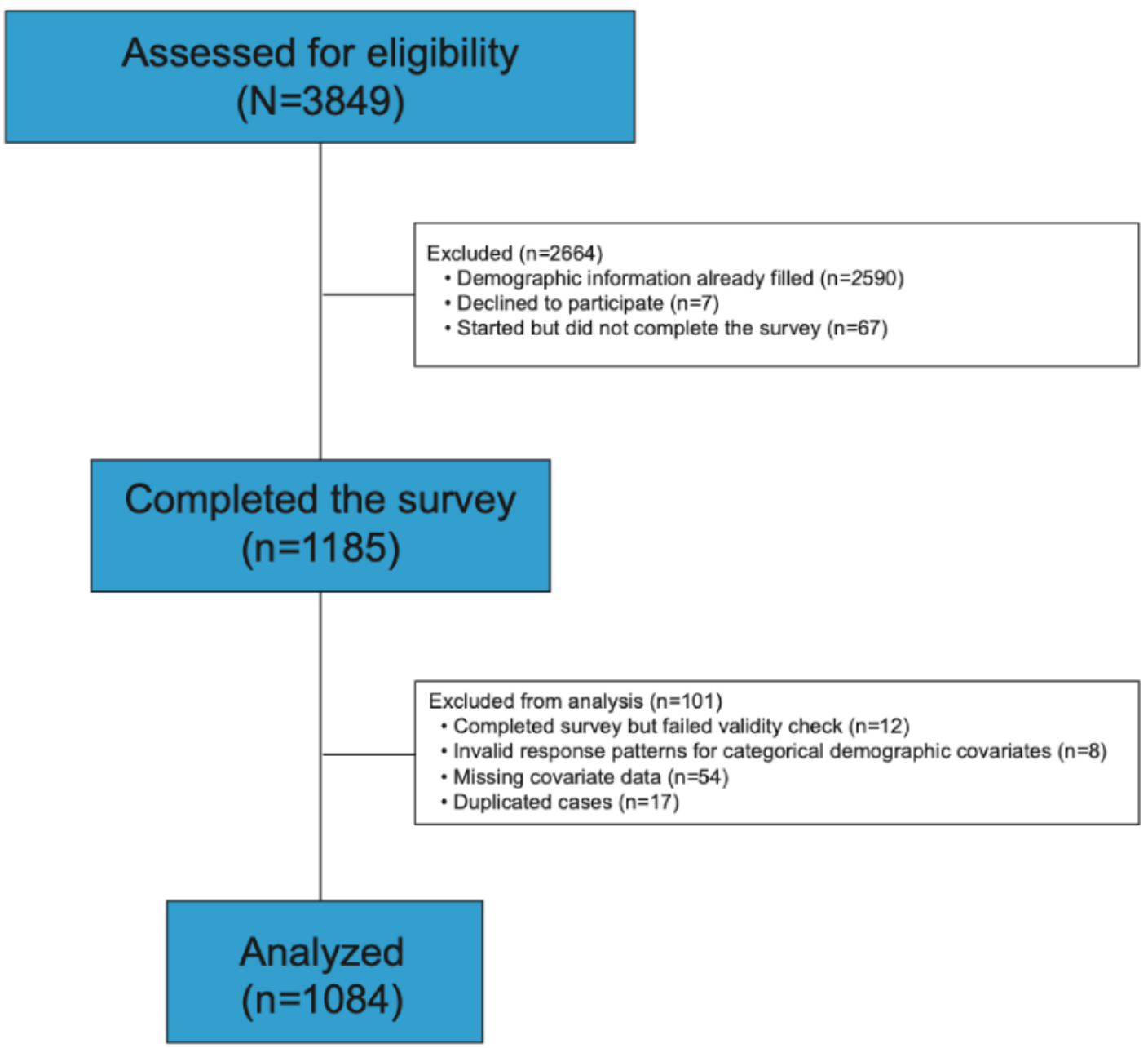


Table 2. Characteristics of the participants $(\mathrm{N}=1084)$ in the web-based survey of health behaviors and Centers for Disease Control and Prevention guideline adherence conducted in June-July 2020.

\begin{tabular}{lll}
\hline Variable & Value & Recode information \\
\hline Age (years), mean (SD) & $40.9(13.4)$ & None \\
Sex (assigned at birth), n (\%) & $\begin{array}{l}\text { We created a combined sex and gender variable recoded to cisgender male if } \\
\text { sex="male" and gender="man" and no other gender endorsed, cisgender female if } \\
\text { sex="female" and gender="woman" and no other gender endorsed, and other for } \\
\text { all other combinations. }\end{array}$ \\
&
\end{tabular}

$\begin{array}{ll}\text { Male } & 540(49.8) \\ \text { Female } & 536(49.5) \\ \text { Prefer not to answer } & 8(0.7)\end{array}$

Gender (select all that apply), n (\%)

$\begin{array}{ll}\text { Man } & 529(48.8) \\ \text { Woman } & 543(50.1) \\ \text { Nonbinary } & 6(0.6) \\ \text { Transgender } & 4(0.4) \\ \text { Other or prefer not to answer } & 9(0.8)\end{array}$

Race (select all that apply), n (\%)

$\begin{array}{ll}\text { White } & 742(68.5) \\ \text { Black or African American } & 267(24.6) \\ \text { American Indian or Alaskan Native } & 26(2.4) \\ \text { Asian Indian } & 34(3.1) \\ \text { Chinese } & 31(2.9) \\ \text { Filipino } & 6(0.5) \\ \text { Japanese } & 3(0.3) \\ \text { Korean } & 7(0.6) \\ \text { Vietnamese } & 1(0.1) \\ \text { Other Asian } & 15(1.4) \\ \text { Native Hawaiian } & 2(0.2) \\ \text { Guamanian or Chamorro } & 1(0.1) \\ \text { Other Pacific Islander } & 5(0.5)\end{array}$

Ethnicity (select all that apply), n (\%)

Not of Hispanic, Latino/Latina, or Spanish Origin

Mexican, Mexican American, or Chicano/Chicana

Puerto Rican

Cuban

155 (14.3)

Another Hispanic, Latino/Latina, or
We created a combined sex and gender variable recoded to cisgender male if sex="male" and gender="man" and no other gender endorsed, cisgender female if sex="female" and gender="woman" and no other gender endorsed, and other for all other combinations.
We created 4 race categories recoded to White if race="White" and no other race endorsed, Black or African American if race="Black or African American" and no other race endorsed, Asian if race=any of "Asian Indian | Chinese | Filipino | Japanese | Korean | Vietnamese | Other Asian" and no other race endorsed; and Other Race or More Than One for all other endorsed categories.
We dichotomized ethnicity to Not of Hispanic, Latino/Latina, or Spanish origin, and all other endorsed categories Spanish origin 


\begin{tabular}{|c|c|c|}
\hline Variable & Value & Recode information \\
\hline College graduate & $547(50.5)$ & \\
\hline Some college & $215(19.8)$ & \\
\hline Professional degree & $215(19.8)$ & \\
\hline High school or lower & $107(9.9)$ & \\
\hline Annual household income, n (\%) & & Eight ordered categories were treated continuously. \\
\hline Less than US $\$ 25,000$ & $123(11.4)$ & \\
\hline US $\$ 25,000-\$ 34,999$ & $122(11.3)$ & \\
\hline US $\$ 35,000-\$ 49,999$ & $152(14.0)$ & \\
\hline US $\$ 50,000-\$ 74,999$ & $287(26.5)$ & \\
\hline US $\$ 75,000-\$ 99,999$ & $188(17.3)$ & \\
\hline US $\$ 100,000-\$ 149,999$ & $139(12.8)$ & \\
\hline US $\$ 150,000-\$ 199,999$ & $39(3.6)$ & \\
\hline US $\$ 200,000$ and above & $34(3.1)$ & \\
\hline Household size & $3.06(1.33)$ & None \\
\hline Dwelling ownership (yes) & $507(46.8)$ & None \\
\hline Essential worker, n (\%) & & Dichotomized to Yes and No or unsure. \\
\hline No & $641(59.1)$ & \\
\hline Yes & $388(35.8)$ & \\
\hline Unsure & $55(5.1)$ & \\
\hline $\begin{array}{l}\text { Centers for Disease Control and Prevention } \\
\text { adherence }\end{array}$ & $2.20(0.62)$ & None \\
\hline COVID-19 testing history, $\mathrm{n}(\%)$ & & None \\
\hline No test or unsure & $805(74.3)$ & \\
\hline Yes & $279(25.7)$ & \\
\hline COVID-19 test result $(\mathrm{n}=279), \mathrm{n}(\%)$ & & Either a positive nasal or blood test was recoded as a positive COVID-19 test result. \\
\hline Negative & $235(84.2)$ & \\
\hline Positive & $44(15.8)$ & \\
\hline \multicolumn{3}{|l|}{ Substance use, n (\%) } \\
\hline Cigarette use (past 7 days) & & Recoded from Timeline Followback \\
\hline None & $865(79.8)$ & \\
\hline Nondaily (1-6 days) & $66(6.1)$ & \\
\hline Daily (7 days) & $153(14.1)$ & \\
\hline \multicolumn{2}{|c|}{ Electronic cigarette use (past 7 days), n (\%) } & Recoded from Timeline Followback \\
\hline None & $995(91.8)$ & \\
\hline Nondaily (1-6 days) & $39(3.6)$ & \\
\hline Daily (7 days) & $50(4.6)$ & \\
\hline Cannabis (past 7 days), n (\%) & & Recoded from Timeline Followback. Includes use of any form of cannabis \\
\hline None & $973(89.8)$ & \\
\hline Nondaily (1-6 days) & $49(4.5)$ & \\
\hline Daily (7 days) & $62(5.7)$ & \\
\hline Alcohol (past 7 days), n (\%) & & Recoded from Timeline Followback \\
\hline None & $643(59.3)$ & \\
\hline Nondaily (1-6 days) & $356(32.8)$ & \\
\hline
\end{tabular}




\begin{tabular}{cll}
\hline Variable & Value & Recode information \\
\hline $\begin{array}{c}\text { Daily (7 days) } \\
\text { Opioids (past 7 days), } \mathbf{n}(\%)\end{array}$ & $85(7.8)$ & Recoded from Timeline Followback. Includes use of any opioids \\
None & $858(79.2)$ & \\
Nondaily (1-6 days) & $180(16.6)$ & \\
Daily (7 days) & $46(4.2)$ & Recoded from Timeline Followback \\
Stimulants (past 7 days), $\mathbf{n}(\%)$ & & \\
None & $1015(93.6)$ & \\
Nondaily (1-6 days) & $42(3.9)$ & \\
Daily (7 days) & $27(2.5)$ &
\end{tabular}

\section{CDC Guideline Adherence}

Covariates tested for inclusion are reported in Table 2. The following variables were statistically related to CDC guideline adherence and retained in the model: gender, ethnicity, essential worker status, income, and COVID-19 test. Covariates accounted for $7.1 \%$ of the variance in CDC guideline adherence ( $R^{2}=0.071$, adjusted $\left.R^{2}=0.057\right)$. Unadjusted relations of substance use variables with CDC guideline adherence scores are provided in Table S2 in Multimedia Appendix 1. Cigarette, alcohol, opioid, and stimulant use were related to CDC guideline adherence scores in bivariate models. In the multivariable model including all substance use variables and significant covariates from Table 1, only alcohol consumption and opioid use were statistically related to CDC guideline adherence. The results of the final model are reported in Table 3. Participants who reported daily opioid use reported lower CDC guideline adherence than participants who reported 1-6 opioid use days or no opioid use. Likewise, participants who reported 1-6 opioid use days reported lower adherence than those who reported no use. Participants who reported 1-6 drinking days reported higher CDC guideline adherence than participants who reported daily drinking or no drinking, whereas daily drinkers and nondrinkers did not differ statistically on CDC adherence. The final model retaining only significant covariates, alcohol use, and opioid use accounted for $12.9 \%$ of the variance in CDC guideline adherence $\left(R^{2}=0.129\right.$, adjusted $\left.R^{2}=0.120\right)$, where the covariate model reported above had accounted for $7.1 \%$ of the variance in CDC guideline adherence. Thus, when considering influences on CDC adherence, alcohol and opioid use contributed nearly as much to understanding adherence as did the combination of gender, ethnicity, essential worker status, income, and COVID-19 test. 
Table 3. General linear model of associations between substance use and Centers for Disease Control and Prevention guideline adherence, accounting for covariates in the full sample of survey participants $(\mathrm{N}=1084)$.

\begin{tabular}{|c|c|c|}
\hline Variable & Unstandardized estimate & $95 \% \mathrm{CI}$ \\
\hline Intercept & 2.26 & 2.19 to 2.37 \\
\hline \multicolumn{3}{|l|}{ Gender } \\
\hline Cisgender female & $\operatorname{Ref}^{\mathrm{a}}$ & Ref \\
\hline Cisgender male & -0.17 & -0.24 to -0.10 \\
\hline Other gender identity or prefer not to answer & -0.42 & -0.62 to -0.21 \\
\hline Hispanic or Latino (Ref: No) & -0.05 & -0.13 to 0.03 \\
\hline Essential worker (Ref: No) & -0.04 & -0.13 to 0.04 \\
\hline Income & 0.02 & 0.004 to 0.04 \\
\hline \multicolumn{3}{|l|}{ COVID-19 test } \\
\hline No test or unsure & Ref & Ref \\
\hline Negative test & 0.10 & 0.01 to 0.19 \\
\hline Positive test & -0.02 & -0.21 to 0.17 \\
\hline \multicolumn{3}{|l|}{ Alcohol use (past 7 days) } \\
\hline Daily versus none & -0.07 & -0.20 to 0.06 \\
\hline $1-6$ days versus none & 0.10 & 0.02 to 0.17 \\
\hline Daily versus $1-6$ days ${ }^{b}$ & -0.16 & -0.30 to -0.02 \\
\hline \multicolumn{3}{|l|}{ Opioid use } \\
\hline Daily versus none & -0.57 & -0.76 to -0.38 \\
\hline $1-6$ days versus none & -0.32 & -0.43 to -0.22 \\
\hline Daily versus 1-6 days ${ }^{b}$ & -0.24 & -0.44 to -0.05 \\
\hline
\end{tabular}

${ }^{\text {a }}$ Ref: reference category.

${ }^{\mathrm{b}}$ Indicates reference groups and additional models for substance use variables where reference groups were switched to allow for additional comparisons.

\section{COVID-19 Testing}

The relation of CDC guideline adherence with COVID-19 testing was also evaluated and found to be not statistically related. Of the covariates in Table 2, the following were related to the likelihood of COVID-19 testing: age, education, race, ethnicity, essential worker status, income, and household size.
Of substance use variables, only opioid use was statistically related to testing likelihood. The results of the final model are reported in Table 4. For a daily opioid user, the odds of reporting COVID-19 testing were 3.35 times as large as the odds for a nonuser and 1.61 times as large as the odds for a participant who used opioids on 1-6 days. 
Table 4. Logistic regression model of associations between substance use and any COVID-19 testing, accounting for covariates in the full sample of survey participants $(\mathrm{N}=1084){ }^{\mathrm{a}}$

\begin{tabular}{|c|c|c|}
\hline Variable & $\begin{array}{l}\text { Unadjusted prevalence and percentage testing within category, } \\
\mathrm{n}(\%)\end{array}$ & Odds ratio $(95 \% \mathrm{CI})$ \\
\hline Age & $\mathrm{N} / \mathrm{A}^{\mathrm{b}}$ & $1.01(1.00-1.02)$ \\
\hline \multicolumn{3}{|l|}{ Education } \\
\hline Graduate or professional degree & $64(29.8)$ & $\operatorname{Ref}^{\mathrm{c}}$ \\
\hline College graduate/4-year degree & $162(29.6)$ & $0.70(0.47-1.05)$ \\
\hline High school or less & $19(17.8)$ & $0.45(0.23-0.86)$ \\
\hline Some college/2-year degree & $34(15.8)$ & $0.41(0.24-0.69)$ \\
\hline Hispanic or Latino & $118(42.8)$ & $1.67(1.18-2.37)$ \\
\hline Not Hispanic or Latino & $161(19.9)$ & Ref \\
\hline \multicolumn{3}{|l|}{ Racial identity } \\
\hline White & $165(23.2)$ & Ref \\
\hline Asian & $9(11.7)$ & $0.66(0.31-1.44)$ \\
\hline Black or African American & $89(37.2)$ & $1.60(1.12-2.30)$ \\
\hline Other or more than one & $16(27.6)$ & $1.26(0.63-2.52)$ \\
\hline Essential worker & $164(42.3)$ & $2.22(1.60-3.09)$ \\
\hline Not essential worker & $115(16.5)$ & Ref \\
\hline Income & N/A & $0.85(0.77-0.94)$ \\
\hline Household size & N/A & $1.33(1.17-1.50)$ \\
\hline \multicolumn{3}{|l|}{ Opioid use } \\
\hline Daily versus none & $32^{\mathrm{d}}\left(69.6^{\mathrm{d}}\right)$ & $3.35(1.63-6.86)$ \\
\hline 1-6 days versus none & $93^{\mathrm{e}}\left(51.7^{\mathrm{e}}\right)$ & $2.08(1.39-3.11)$ \\
\hline Daily versus 1-6 days & $154^{\mathrm{f}}\left(18.0^{\mathrm{f}}\right)$ & $1.61(0.78-3.34)$ \\
\hline
\end{tabular}

${ }^{\mathrm{a}}$ Italicized text indicates reference groups and additional models for substance use variables where reference groups were switched to allow for additional comparisons. Unadjusted prevalence values are provided for categorical variables only.

${ }^{\mathrm{N}} \mathrm{N} / \mathrm{A}$ : not applicable.

${ }^{\mathrm{c}}$ Ref: reference category.

${ }^{\mathrm{d}}$ Daily.

${ }^{\mathrm{e}} 1-6$ days.

${ }^{\mathrm{f}}$ None.

Following the finding that daily and nondaily opioid users were more likely to receive a COVID-19 test, we conducted 2 post hoc analyses on factors that might plausibly lead to higher testing rates in opioid users. First, we asked whether opioid users had significantly higher rates of comorbid medical conditions known to increase the risk of COVID-19 in their households by comparing the count of how many of the following conditions were endorsed by the participants: autoimmune disease, cardiovascular disease, cerebrovascular disease, chronic lung disease, diabetes, immune compromise, or kidney disease. Independent $t$ tests showed no difference in this count of medical conditions between daily users versus nonusers $\left(\mathrm{t}_{902}=-0.016, P=.98\right)$ or between nondaily users versus nonusers $\left(\mathrm{t}_{1036}=-1.333, P=.18\right)$. Second, we asked whether engagement in medication-assisted treatment (MAT) for opioid use disorder was associated with a higher likelihood of receiving a COVID-19 test. In the total sample, MAT was endorsed by $61 \%$ (28/46) of daily opioid users, $32.2 \%$ (58/180) of nondaily opioid users, and $2.1 \%$ (18/858) of nonusers. Among opioid users, $40.7 \%$ (57/140) of opioid users not engaged in MAT received a COVID-19 test, whereas 79\% (68/86) of opioid users engaged in MAT received a COVID-19 test. This difference was significant (Pearson $\chi^{2}{ }_{1}=31.8, P<.001$ ). In summary, MAT engagement was associated with higher rates of COVID-19 testing in nondaily and daily opioid users. The likelihood of a positive result was evaluated among the subset who received a COVID-19 test. The following Table 2 covariates were statistically related to a positive result: ethnicity, household size, and dwelling ownership. Of substance use variables, only stimulant use statistically related to testing likelihood. The results of the final model are reported in Table 5. For a daily stimulant user, the odds of reporting a positive COVID-19 test 
among those who were tested was significantly higher for daily users than that for either nonusers or those who reported use on 1-6 days. There was no statistically significant difference in receiving a positive COVID-19 test for nondaily stimulant users versus nonusers.

Table 5. Logistic model of associations of stimulant use with positive COVID-19 test result, accounting for covariates, in the subset of participants reporting a COVID-19 test $(\mathrm{n}=279){ }^{\mathrm{a}}$

\begin{tabular}{lll}
\hline Variable & \multicolumn{2}{l}{ Unadjusted prevalence and percentage testing within category, } \\
& $\mathrm{n}(\%)$ & Odds ratio (95\% CI) \\
\hline Hispanic or Latino & $28(23.7)$ & $2.00(1.96-4.19)$ \\
Not Hispanic or Latino & $16(9.9)$ & $\operatorname{Ref}^{\mathrm{b}}$ \\
Household size & $\mathrm{N} / \mathrm{A}^{\mathrm{c}}$ & $1.49(1.08-2.07)$ \\
Dwelling ownership & $15(11.2)$ & $0.45(0.21-0.95)$ \\
No dwelling ownership & $29(20.0)$ & Ref \\
Stimulant use & & $10.49(3.19-34.44)$ \\
\multicolumn{1}{c}{ Daily versus none } & $12^{\mathrm{d}}\left(70.6^{\mathrm{d}}\right)$ & $1.44(0.49-4.25)$ \\
\multicolumn{1}{c}{ 1-6 days versus none } & $5^{\mathrm{e}}\left(18.5^{\mathrm{e}}\right)$ & $7.29(1.66-32.05)$ \\
\multicolumn{1}{c}{ Daily versus 1-6 days } & $27^{\mathrm{f}}\left(11.5^{\mathrm{f}}\right)$ & \\
\hline
\end{tabular}

${ }^{\mathrm{a}}$ Italicized text indicates reference groups and additional models for substance use variables where reference groups were switched to allow for additional comparisons. Unadjusted prevalence values are provided for categorical variables only.

${ }^{\mathrm{b}}$ Ref: reference category.

${ }^{\mathrm{c}} \mathrm{N} / \mathrm{A}$ : not applicable.

${ }^{\mathrm{d}}$ Daily.

e 1-6 days.

${ }^{\mathrm{f}}$ None.

\section{Discussion}

\section{Principal Results}

This study tested the hypothesis that heavier substance use would be associated with lower adherence to CDC guidelines to reduce the spread of COVID-19. Our geographic focus was 5 states that had experienced the highest rates of COVID infection and deaths at the time of the survey [24]. Our hypothesis was partially supported in that daily drinkers reported lower adherence than those who drank 1-6 days per week, and daily opioid users reported lower adherence than those who used opioids 1-6 days per week or not at all. However, we did not observe statistical associations of cigarettes, e-cigarettes, cannabis, or stimulant use with CDC guideline adherence, after accounting for sociodemographic covariates and other substance use variables.

Use of some substances was related to the likelihood either of receiving a COVID-19 test or of receiving a positive test. The odds of COVID-19 testing were 3.35 times as large for daily opioid users as for nonusers and 2.08 times as large for nondaily opioid users as for nonusers. Post hoc analyses showed that opioid users did not have significantly higher rates of comorbid medical conditions than nonusers, but they did report high rates of engagement in MAT for opioid use disorder. In turn, MAT was associated with significantly higher rates of COVID-19 testing in opioid users. Although speculative, it is possible that engagement in MAT increased contact with the health care system and thereby increased testing rates in opioid users. In addition, among those who received a COVID-19 test, odds of a positive test were significantly higher in daily stimulant users than those who used stimulants less frequently or not at all. There is a large body of research linking the use of amphetamine, methamphetamine, and other stimulants to HIV transmission, largely through risky sexual behavior [36-38]. Although sexual contact is not central to COVID-19 transmission, it may be that stimulant users had a riskier pattern of in-person contacts (eg, more frequent or less observant of distancing) that increased their risk of COVID-19 infection.

Cigarette use was associated with CDC guideline adherence in unadjusted analyses; yet, this variable became nonsignificant after adjusting for sociodemographic characteristics and other substance use. This pattern suggests that other characteristics or behaviors associated with cigarette use are driving the finding. Null results observed for e-cigarette, cannabis, and stimulant use should be interpreted within the limits of the study design and sample size. The prevalence of nondaily or daily e-cigarette, cannabis, and stimulant use was less than 6\%. For these substances, the study may not have had sufficient power to detect differences in CDC adherence scores.

In the final model, gender, income, and COVID-19 test history were the demographic covariates that remained significant after the inclusion of substance use variables. Women reported higher adherence than men and those with other gender identities, and income showed a positive linear association with adherence. These findings are consistent with previous research $[15,17]$. Participants with a negative COVID-19 test reported higher 
adherence than those who had not had a test or were unsure. There was no difference in the adherence between those reporting a negative versus positive test result. The reason for this finding is unclear but may involve higher vigilance in those who had received a negative test result. Although we oversampled Black and Hispanic individuals to ensure representation, neither race nor ethnicity was a significant predictor of CDC guideline adherence after accounting for substance use.

Substance use is a known risk factor for COVID-19 infection [1]. A major implication of our findings is that lower behavioral adherence to CDC guidelines may be one mechanism by which substance use increases risk for COVID-19 infection. These findings should not be used to further stigmatize these individuals, who already face considerable stigma and adversity in social, occupational, and health care settings. Rather, results reinforce the need for outreach efforts and interventions that support behavioral adherence, COVID-19 testing, and vaccination for this population. Limited previous research has addressed this topic. We did not replicate the finding that use of e-cigarettes and combustible cigarettes was associated with COVID-19 testing and positive diagnosis [39]. However, that study was limited to individuals aged 13-24 years, which differs from our adult population.

Interestingly, individuals who drank 1-6 days per week reported higher CDC guideline adherence relative to nondrinkers and daily drinkers who did not differ statistically from each other. This finding may be in line with other observational research linking moderate or occasional alcohol consumption to health behaviors such as physical activity $[40,41]$. This interpretation is speculative as alcohol quantity was not included in the model, and therefore, nondaily drinkers, nevertheless, may have engaged in heavy episodic drinking. Given the present findings regarding alcohol consumption and COVID-19, further work in this space is warranted.

\section{Limitations}

The limitations of this study include the use of a nonrepresentative convenience sample, self-report data, and a novel CDC adherence scale that has not yet been validated. The survey did not explicitly assess the number or timing of COVID-19 tests that participants had received. Absence of data on the timing of testing is a significant limitation particularly with regard to understanding the relation with substance use. Analyses accounted for frequency but not quantity of substance use or specific patterns of polysubstance use, both of which are potentially important factors that warrant attention in future research. Our findings may not generalize to the US population as a whole. For effects with large confidence intervals, findings should be interpreted as informing directionality for future research rather than representing a reliable estimate of their magnitude in the sampled population.

\section{Conclusions}

In a convenience sample of adults living in the northeastern United States, we found that daily use of alcohol or opioids was significantly associated with lower adherence to CDC guidelines for reducing the spread of COVID-19, after accounting for sociodemographic characteristics and other substance use. However, use of cigarettes, e-cigarettes, cannabis, or stimulants was not associated with adherence. We also found that daily use of nonprescribed opioids was associated with higher odds of COVID-19 testing and that daily use of stimulants was associated with higher odds of a positive COVID-19 test result. The strengths of this study include the calendar-based assessment of several common classes of substances and the racial, ethnic, and age diversity of the sample. The findings of this study point to a need for public health efforts to support behavioral adherence and to expand COVID-19 testing and vaccination in individuals with high levels of alcohol, opioid, or stimulant use.

\section{Acknowledgments}

This project was supported by an Institutional Development Award from the National Institute of General Medical Sciences of the National Institutes of Health under grant P20GM130414 (Monti). Preparation of the report was also supported by National Institutes of Health grants K23AA024704 (Monnig), K01DA039311 (Aston), K01AA023867, R01AA026589, R01AA027760, R21AA027614 (Haass-Koffler), K08DA048137 (Sokolovsky), and K23AA024808 (Treloar Padovano).

\section{Conflicts of Interest}

None declared.

\section{Multimedia Appendix 1}

Supplemental tables.

[DOCX File, 17 KB-Multimedia Appendix 1]

\section{References}

1. Wang QQ, Kaelber DC, Xu R, Volkow ND. COVID-19 risk and outcomes in patients with substance use disorders: analyses from electronic health records in the United States. Mol Psychiatry 2021 Jan;26(1):30-39 [FREE Full text] [doi: 10.1038/s41380-020-00880-7] [Medline: 32929211]

2. COVID-19 and people at increased risk. Centers for Disease Control and Prevention. URL: https://www.cdc.gov/coronavirus/ 2019-ncov/need-extra-precautions/other-at-risk-populations/people-who-use-drugs/QA.html [accessed 2005-01-01] 
3. Volkow ND. Collision of the COVID-19 and Addiction Epidemics. Annals of Internal Medicine 2020 Jul 07;173(1):61-62. [doi: $10.7326 / \mathrm{m} 20-1212$ ]

4. Pollard MS, Tucker JS, Green HD. Changes in Adult Alcohol Use and Consequences During the COVID-19 Pandemic in the US. JAMA Netw Open 2020 Sep 01;3(9):e2022942 [FREE Full text] [doi: 10.1001/jamanetworkopen.2020.22942] [Medline: 32990735]

5. Bailey KL, Samuelson DR, Wyatt TA. Alcohol use disorder: A pre-existing condition for COVID-19? Alcohol 2021 Feb;90:11-17 [FREE Full text] [doi: 10.1016/j.alcohol.2020.10.003] [Medline: 33080339]

6. Iacono WG, Malone SM, McGue M. Behavioral disinhibition and the development of early-onset addiction: common and specific influences. Annu Rev Clin Psychol 2008;4:325-348. [doi: 10.1146/annurev.clinpsy.4.022007.141157] [Medline: 18370620]

7. Czeisler, Lane RI, Petrosky E, Wiley JF, Christensen A, Njai R, et al. Mental Health, Substance Use, and Suicidal Ideation During the COVID-19 Pandemic - United States, June 24-30, 2020. MMWR Morb Mortal Wkly Rep 2020 Aug 14;69(32):1049-1057 [FREE Full text] [doi: 10.15585/mmwr.mm6932a1] [Medline: 32790653]

8. Barbosa C, Cowell A, Dowd W. Webinar: how has drinking behavior changed during the COVID-19 pandemic? RTI International. URL: https://www.rti.org/event/webinar-how-has-drinking-behavior-changed-during-covid-19-pandemic [accessed 2021-11-01]

9. Gaiha SM, Lempert LK, Halpern-Felsher B. Underage Youth and Young Adult e-Cigarette Use and Access Before and During the Coronavirus Disease 2019 Pandemic. JAMA Netw Open 2020 Dec 01;3(12):e2027572 [FREE Full text] [doi: 10.1001/jamanetworkopen.2020.27572] [Medline: 33270127]

10. Sokolovsky AW, Hertel AW, Micalizzi L, White HR, Hayes KL, Jackson KM. Preliminary impact of the COVID-19 pandemic on smoking and vaping in college students. Addict Behav 2021 Apr;115:106783 [FREE Full text] [doi: 10.1016/j.addbeh.2020.106783] [Medline: 33360444]

11. Ahmad F, Rossen L, Sutton P. Provisional drug overdose death counts. National Center for Health Statistics. URL: https:/ /www.cdc.gov/nchs/nvss/vsrr/drug-overdose-data.htm [accessed 2021-11-01]

12. Centers FDCAP. Overdose deaths accelerating during COVID-19. Centers for Disease Control and Prevention. URL: https:/ /www.cdc.gov/media/releases/2020/p1218-overdose-deaths-covid-19.html [accessed 2021-05-02]

13. Implementation of mitigation strategies for communities with local COVID-19 transmission. Centers for Disease Control and Prevention. URL: https://www.cdc.gov/coronavirus/2019-ncov/community/community-mitigation.html [accessed 2001-01-01]

14. Suffoletto B, Ram N, Chung T. In-Person Contacts and Their Relationship With Alcohol Consumption Among Young Adults With Hazardous Drinking During a Pandemic. J Adolesc Health 2020 Nov;67(5):671-676 [FREE Full text] [doi: 10.1016/j.jadohealth.2020.08.007] [Medline: 32943290]

15. Qeadan F, Akofua Mensah N, Tingey B, Bern R, Rees T, Talboys S, et al. What Protective Health Measures Are Americans Taking in Response to COVID-19? Results from the COVID Impact Survey. Int J Environ Res Public Health 2020 Aug 29;17:17 [FREE Full text] [doi: 10.3390/ijerph17176295] [Medline: 32872439]

16. Fridman I, Lucas N, Henke D, Zigler CK. Association Between Public Knowledge About COVID-19, Trust in Information Sources, and Adherence to Social Distancing: Cross-Sectional Survey. JMIR Public Health Surveill 2020 Sep 15;6(3):e22060 [FREE Full text] [doi: 10.2196/22060] [Medline: $\underline{\text { 32930670] }}$

17. Czeisler, Tynan MA, Howard ME, Honeycutt S, Fulmer EB, Kidder DP, et al. Public Attitudes, Behaviors, and Beliefs Related to COVID-19, Stay-at-Home Orders, Nonessential Business Closures, and Public Health Guidance - United States, New York City, and Los Angeles, May 5-12, 2020. MMWR Morb Mortal Wkly Rep 2020 Jun 19;69(24):751-758 [FREE Full text] [doi: $10.15585 / \mathrm{mmwr} . \mathrm{mm} 6924 \mathrm{e} 1$ ] [Medline: $\underline{32555138}$ ]

18. Hutchins HJ, Wolff B, Leeb R, Ko JY, Odom E, Willey J, et al. COVID-19 Mitigation Behaviors by Age Group - United States, April-June 2020. MMWR Morb Mortal Wkly Rep 2020 Oct 30;69(43):1584-1590 [FREE Full text] [doi: 10.15585/mmwr.mm6943e4] [Medline: 33119562]

19. Nollen NL, Mayo MS, Sanderson Cox L, Benowitz NL, Tyndale RF, Ellerbeck EF, et al. Factors That Explain Differences in Abstinence Between Black and White Smokers: A Prospective Intervention Study. J Natl Cancer Inst 2019 Oct 01;111(10):1078-1087 [FREE Full text] [doi: 10.1093/jnci/djz001] [Medline: $\underline{\text { 30657926] }}$

20. Kees J, Berry C, Burton S, Sheehan K. An Analysis of Data Quality: Professional Panels, Student Subject Pools, and Amazon's Mechanical Turk. Journal of Advertising 2017 Jan 23;46(1):141-155. [doi: 10.1080/00913367.2016.1269304]

21. Zhang B, Gearhart S. Surv Pract 2020 Dec 03;13(1):1-10. [doi: 10.29115/sp-2020-0015]

22. Robinson J, Rosenzweig C, Moss AJ, Litman L. Tapped out or barely tapped? Recommendations for how to harness the vast and largely unused potential of the Mechanical Turk participant pool. PLoS One 2019;14(12):e0226394 [FREE Full text] [doi: 10.1371/journal.pone.0226394] [Medline: 31841534]

23. Hitlin P. Research in the crowdsourcing age, a case study. Pew Research Center. URL: http://www.pewinternet.org/2016/ 07/11/research-in-the-crowdsourcing-age-a-case-study/ [accessed 2021-11-01]

24. Dong E, Du H, Gardner L. An interactive web-based dashboard to track COVID-19 in real time. Lancet Infect Dis 2020 May;20(5):533-534 [FREE Full text] [doi: 10.1016/S1473-3099(20)30120-1] [Medline: 32087114] 
25. Monti P, Tidey J, Ahluwalia J. Brown University COBRE Center for Addiction and Disease Risk Exacerbation. R I Med J (2013) 2021 Apr 01;104(3):27-31 [FREE Full text] [Medline: 33789405]

26. Price-Haywood EG, Burton J, Fort D, Seoane L. Hospitalization and Mortality among Black Patients and White Patients with Covid-19. N Engl J Med 2020 Jun 25;382(26):2534-2543 [FREE Full text] [doi: 10.1056/NEJMsa2011686] [Medline: $\underline{32459916}$ ]

27. Raisi-Estabragh Z, McCracken C, Bethell MS, Cooper J, Cooper C, Caulfield MJ, et al. Greater risk of severe COVID-19 in Black, Asian and Minority Ethnic populations is not explained by cardiometabolic, socioeconomic or behavioural factors, or by 25(OH)-vitamin D status: study of 1326 cases from the UK Biobank. J Public Health (Oxf) 2020 Aug 18;42(3):451-460 [FREE Full text] [doi: 10.1093/pubmed/fdaa095] [Medline: $\underline{\text { 32556213] }}$

28. Rentsch CT, Kidwai-Khan F, Tate JP, Park LS, King JT, Skanderson M, et al. Covid-19 Testing, Hospital Admission, and Intensive Care Among 2,026,227 United States Veterans Aged 54-75 Years. medRxiv Preprint posted online on Apr 14, 2020 [FREE Full text] [doi: 10.1101/2020.04.09.20059964] [Medline: 32511595]

29. Rentsch CT, Kidwai-Khan F, Tate JP, Park LS, King JT, Skanderson M, et al. Covid-19 by Race and Ethnicity: A National Cohort Study of 6 Million United States Veterans. medRxiv Preprint posted online on May 18, 2020 [FREE Full text] [doi: 10.1101/2020.05.12.20099135] [Medline: $\underline{32511524]}$

30. Stokes EK, Zambrano LD, Anderson KN, Marder EP, Raz KM, El Burai Felix S, et al. Coronavirus Disease 2019 Case Surveillance - United States, January 22-May 30, 2020. MMWR Morb Mortal Wkly Rep 2020 Jun 19;69(24):759-765 [FREE Full text] [doi: 10.15585/mmwr.mm6924e2] [Medline: 32555134]

31. Keeter S, McGeeney K. Coverage error in internet surveys. Pew Research Center. URL: https://www.pewresearch.org/ methods/2015/09/22/coverage-error-in-internet-surveys/ [accessed 2021-05-30]

32. Household pulse survey questionnaire - phase 1. United States Census Bureau. URL: https://www.census.gov/ programs-surveys/household-pulse-survey/data.html [accessed 2020-12-01]

33. Sobell L, Sobell M. Measuring Alcohol Consumption: Psychosocial and Biological Methods. Totowa, NJ: Humana Press; 1992:41-72.

34. Monnig M, Padovano H, Sokolovsky A. Preregistration template from AsPredicted.org. OSF Registries. URL: https://osf. io/b69ky [accessed 2011-03-03]

35. R Core Team. R: A language and environment for statistical computing. R Foundation for Statistical Computing. URL: https://www.gbif.org/tool/81287/r-a-language-and-environment-for-statistical-computing [accessed 2021-11-01]

36. Colfax G, Santos G, Chu P, Vittinghoff E, Pluddemann A, Kumar S, et al. Amphetamine-group substances and HIV. Lancet 2010 Aug 07;376(9739):458-474. [doi: 10.1016/S0140-6736(10)60753-2] [Medline: 20650520]

37. Shoptaw S, Montgomery B, Williams CT, El-Bassel N, Aramrattana A, Metsch L, et al. Not just the needle: the state of HIV-prevention science among substance users and future directions. J Acquir Immune Defic Syndr 2013 Jul;63 Suppl 2:S174-S178 [FREE Full text] [doi: 10.1097/QAI.0b013e3182987028] [Medline: 23764632]

38. Vu NTT, Maher L, Zablotska I. Amphetamine-type stimulants and HIV infection among men who have sex with men: implications on HIV research and prevention from a systematic review and meta-analysis. J Int AIDS Soc 2015;18:19273 [FREE Full text] [doi: 10.7448/IAS.18.1.19273] [Medline: 25609214]

39. Gaiha SM, Cheng J, Halpern-Felsher B. Association Between Youth Smoking, Electronic Cigarette Use, and COVID-19. J Adolesc Health 2020 Oct;67(4):519-523 [FREE Full text] [doi: 10.1016/j.jadohealth.2020.07.002] [Medline: 32798097]

40. Barrett DH, Anda RF, Croft JB, Serdula MK, Lane MJ. The association between alcohol use and health behaviors related to the risk of cardiovascular disease: the South Carolina Cardiovascular Disease Prevention Project. J Stud Alcohol 1995 Jan;56(1):9-15. [doi: 10.15288/jsa.1995.56.9] [Medline: 7752639]

41. French MT, Popovici I, Maclean JC. Do alcohol consumers exercise more? Findings from a national survey. Am J Health Promot 2009;24(1):2-10. [doi: 10.4278/ajhp.0801104] [Medline: 19750956]

\author{
Abbreviations \\ CDC: Centers for Disease Control and Prevention \\ e-cigarette: electronic cigarette \\ MAT: medication-assisted treatment \\ MTurk: Mechanical Turk
}


Edited by T Sanchez; submitted 01.04.21; peer-reviewed by T Chung, D Kaelber; comments to author 06.05.21; revised version received 11.06.21; accepted 21.09.21; published 09.11.21

Please cite as:

Monnig MA, Treloar Padovano H, Sokolovsky AW, DeCost G, Aston ER, Haass-Koffler CL, Szapary C, Moyo P, Avila JC, Tidey JW, Monti PM, Ahluwalia JS

Association of Substance Use With Behavioral Adherence to Centers for Disease Control and Prevention Guidelines for COVID-19

Mitigation: Cross-sectional Web-Based Survey

JMIR Public Health Surveill 2021;7(11):e29319

URL: https://publichealth.jmir.org/2021/11/e29319

doi: $10.2196 / 29319$

PMID: 34591780

CMollie A Monnig, Hayley Treloar Padovano, Alexander W Sokolovsky, Grace DeCost, Elizabeth R Aston, Carolina L Haass-Koffler, Claire Szapary, Patience Moyo, Jaqueline C Avila, Jennifer W Tidey, Peter M Monti, Jasjit S Ahluwalia. Originally published in JMIR Public Health and Surveillance (https://publichealth.jmir.org), 09.11.2021. This is an open-access article distributed under the terms of the Creative Commons Attribution License (https://creativecommons.org/licenses/by/4.0/), which permits unrestricted use, distribution, and reproduction in any medium, provided the original work, first published in JMIR Public Health and Surveillance, is properly cited. The complete bibliographic information, a link to the original publication on https://publichealth.jmir.org, as well as this copyright and license information must be included. 